\title{
BMJ Open A longitudinal, multicentre, cohort study of community rehabilitation service delivery in long-term neurological conditions
}

\author{
Richard J Siegert, ${ }^{1}$ Diana M Jackson, ${ }^{2}$ E Diane Playford, ${ }^{3}$ Simon Fleminger, ${ }^{4}$ \\ Lynne Turner-Stokes ${ }^{2,5}$
}

To cite: Siegert RJ, Jackson DM, Playford ED, et al. A longitudinal, multicentre, cohort study of community rehabilitation service delivery in long-term neurological conditions. BMJ Open 2014;4:e004231. doi:10.1136/bmjopen-2013004231

- Prepublication history for this paper is available online. To view these files please visit the journal online (http://dx.doi.org/10.1136/ bmjopen-2013-004231).

Received 11 October 2013 Revised 10 January 2014 Accepted 24 January 2014

CrossMark

For numbered affiliations see end of article.

Correspondence to: Professor Richard J Siegert; richard.siegert@aut.ac.nz

\section{ABSTRACT}

Objectives: Part $A$ : To pilot the use of a register to identify and monitor patients with complex needs arising from long-term neurological conditions. Part $B$ : To determine the extent to which patients' needs for health and social services are met following discharge to the community after inpatient rehabilitation; to identify which factors predict unmet needs and to explore the relationship between service provision and outcomes at 12 months.

Design: A multicentre, prospective, cohort study surveying participants at 1,6 and 12 months using postal/online questionnaires and telephone interview. Setting: Consecutive discharges to the community from all nine tertiary, specialist, inpatient neurorehabilitation services in London over 18 months in 2010-2011.

Participants: Of 576 admissions 428 patients were recruited at discharge: 256 responded at 4 weeks, 212 at 6 months and 190 at 12 months.

Measures: Neurological Impairment Scale, The Needs and Provision Complexity Scale, The Northwick Park Dependency Scale, Community Integration Questionnaire, Zarit Burden Inventory.

Results: $n=322(75 \%)$ expressed willingness to be registered, but in practice less than half responded to questionnaires at 6 and 12 months ( $49 \%$ and $44 \%$, respectively), despite extensive efforts to contact them, with no significant differences between responders and non-responders. Significant unmet needs were identified within the first year following discharge, particularly in rehabilitation, social work support and provision of specialist equipment. Dependency for basic care and motor and cognitive impairment predicted services received, together accounting for $40 \%$ of the variance. Contra to expectation, patients whose rehabilitation needs were met were more dependent and less well integrated at 12 months post discharge than those with unmet needs.

Conclusions: Registration is acceptable to most patients, but questionnaires/telephone interviews may not be the most efficient way to reach them. When community resources are limited, service provision tends to be focused on the most dependent patients.
Strengths and limitations of this study

- This study provides the first detailed longitudinal examination of services provided in the community in relation to needs at discharge for a large cohort of patients discharged from specialist neurorehabilitation services in the UK.

- This study identified significant gaps in service provision of both health and social services support in comparison with individual needs.

- This study demonstrates that a LTNC registry would be feasible and acceptable to most patients and that face-to-face interviews conducted as part of integrated care planning are likely to comprise an essential element of such a register.

- The study had a high attrition rate and participants were only recruited from the London Region.

- A limitation of this study was that needs were only assessed at discharge so it was not possible to determine whether under-provision of services reflected unmet needs or changing levels of need.

Registration: The study was registered with the NIHR Comprehensive Local Research Network: ID number 7503

\section{INTRODUCTION}

There is increasing recognition internationally of the importance of postacute community rehabilitation services for long-term neurological conditions (LTNCs), and also the need to demonstrate their cost effectiveness. ${ }^{1-5}$ There has also been increased recognition of the needs and burden experienced by the families and carers of people with LTNCs. ${ }^{6}{ }^{7}$ While some progress has been made in demonstrating the value of community programmes for specific conditions such as traumatic brain injury and stroke, comparatively little is known about the 
organisation, delivery and effectiveness of generic rehabilitation services in the community, in spite of the fact that they constitute the majority of rehabilitation services. ${ }^{8-11}$

LTNCs affect not only the individuals concerned but also their family and carers. In the UK, a series of National Service Frameworks (NSF) have laid down standards for service provision across a wide range of conditions. ${ }^{12}$ Published in 2005 with a 10-year implementation plan, the primary focus of the UK NSF for Long-term Conditions was on neurological conditions. ${ }^{13}$

This NSF sets out 11 standards or 'quality requirements' for rehabilitation and social support for patients living with neurological disability. ${ }^{13}$ It emphasises a biopsychosocial approach, addressing all stages in the "care pathway' from diagnosis to death (see figure 1A), and highlights in particular the need for life-long access to services in the community. ${ }^{14}$ Quality requirement 1 (the 'backbone' standard of the NSF for LTNC) recommends that patients with complex needs should have integrated care planning with regular reviews and a single point of contact to coordinate interagency input (http://www. ltnc.org.uk/index.html; accessed 9 January 2014).

LTNCs represent a diverse group of conditions, encompassing people with widely different needs for services, against which the adequacy of service provision must be judged. Unfortunately, these needs are largely unreported through current information systems, so the epidemiology of 'need' for healthcare and social support is not fully understood. ${ }^{15}$ Previous reports have highlighted a paucity of knowledge about how rehabilitation and support services are delivered in the community, compared with hospital-based services ${ }^{16}$ - and also that community-based care is often fragmented. ${ }^{17}$ Particular concerns were raised about lack of support for patients with complex needs arising from 'hidden disabilities' due to cognitive/behavioural problems, and the impact of these problems on their families. ${ }^{17}$

To support implementation of the NSF for LTNC, in 2006 the UK Department of Health commissioned the NHS Information Centre to develop an LTNC dataset for monitoring implementation and for benchmarking performance against the NSF quality requirements. An LTNC Dataset Development Group consisting of clinicians, data analysts, information technologists and patient/carer representatives was convened with the brief to develop an LTNC dataset that met the standards for approval by the UK Information Standards Board. Published in 2009 the LTNC database brought together a series of discrete datasets to capture episodes of health and social care as the patient moved through the care pathway from diagnosis to end-of-life care. As part of that development, the Dataset Development Group recommended the establishment of an LTNC register to identify those patients with complex needs arising from LTNC and to support integrated care planning and long-term follow-up, in order to monitor their changing needs over time and the services provided to support them (http://www.csi.kcl.ac.uk/community_rehabilitation.html; accessed 9 January 2014). A register was considered the only reliable way to identify those individuals who need (and want) on-going integrated care planning against which the successful implementation of the backbone NSF standard could be judged on a longitudinal basis.

A disease or case-register is a database that attempts 'to identify all cases of a disease or condition in an identified denominator population'. ${ }^{18}$ This definition distinguishes a register from a clinical database, which lacks a defined denominator population and does not attempt to identify all the cases in a specified population. The target population for the LTNC register is the subgroup of patients with complex needs who require integrated service provision from a range of health and social care agencies. Existing coding systems in the UK are primarily based on diagnosis (eg, International Classification of Diseases (ICD)-10 codes in secondary care and Read codes in primary care), which is generally a poor indicator of needs for services. The LTNC register therefore includes a brief dataset for prospective data collection to confirm that the registered patient has:

A. A neurological condition that is likely to have an enduring effect;

B. Complex needs for care/support that are likely to require integrated care planning, either now or in the relatively near future.

In 2009, the UK National Institute for Health Research (NIHR) funded a project to develop and pilot the LTNC register, and to use this to follow longitudinally a cohort of patients with complex needs arising from LTNCs. The purpose of the study was to refine the LTNC register and its associated dataset, and then to use this to examine the extent to which patients' current needs for health and social services were met, to identify any gaps in service provision, and to examine the extent to which meeting their needs might lead to improved outcomes.

This article is divided into two parts:

- In part A, we describe the further development and piloting of the proposed LTNC register and a feasible dataset that could be used in the course of routine practice to monitor needs, inputs and outcomes for people with LTNCs in the community.

- In part B, we used the dataset to follow a cohort of patients with complex neurological disability for a 1-year period after discharge from tertiary inpatient specialist rehabilitation services, to address the following research questions:

- Do patients want to be entered on an LTNC register?

- What proportion of patients would use such a register, and are there any characteristics that identify those patients most likely to do so?

- To what extent are their needs met and what are the main gaps in service provision?

- What predicts the extent of health and social care services received? 


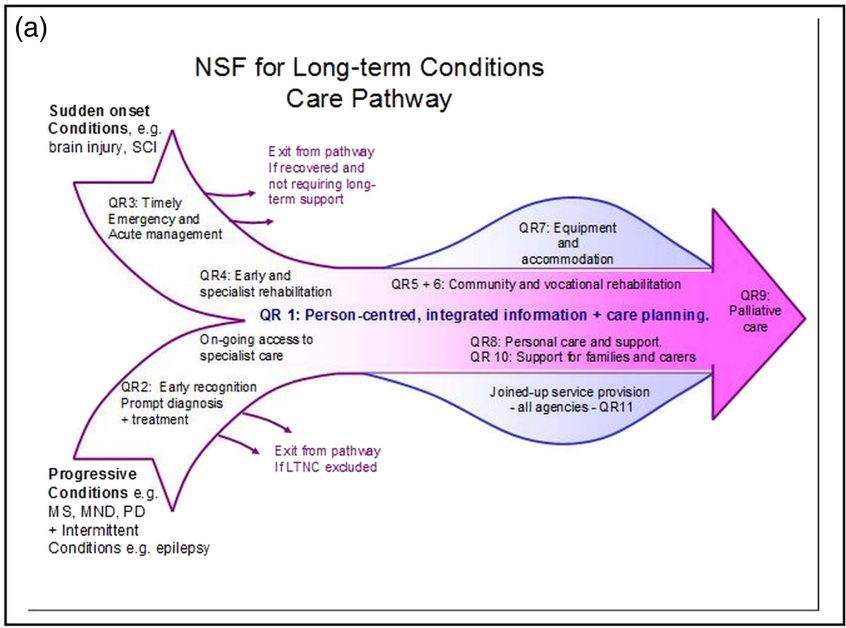

\section{Cross sectional cut:}

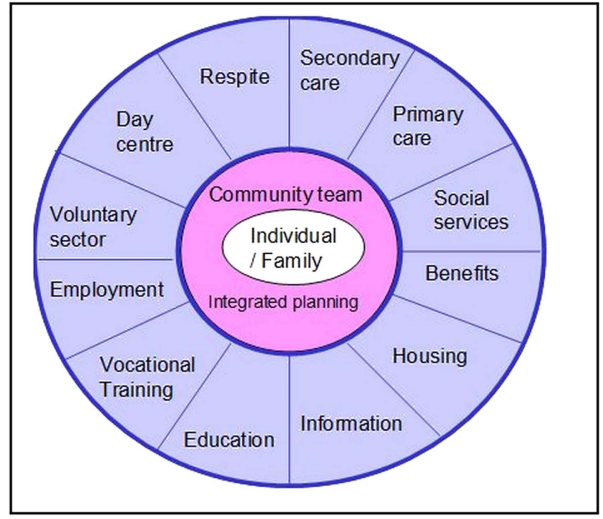

(b)

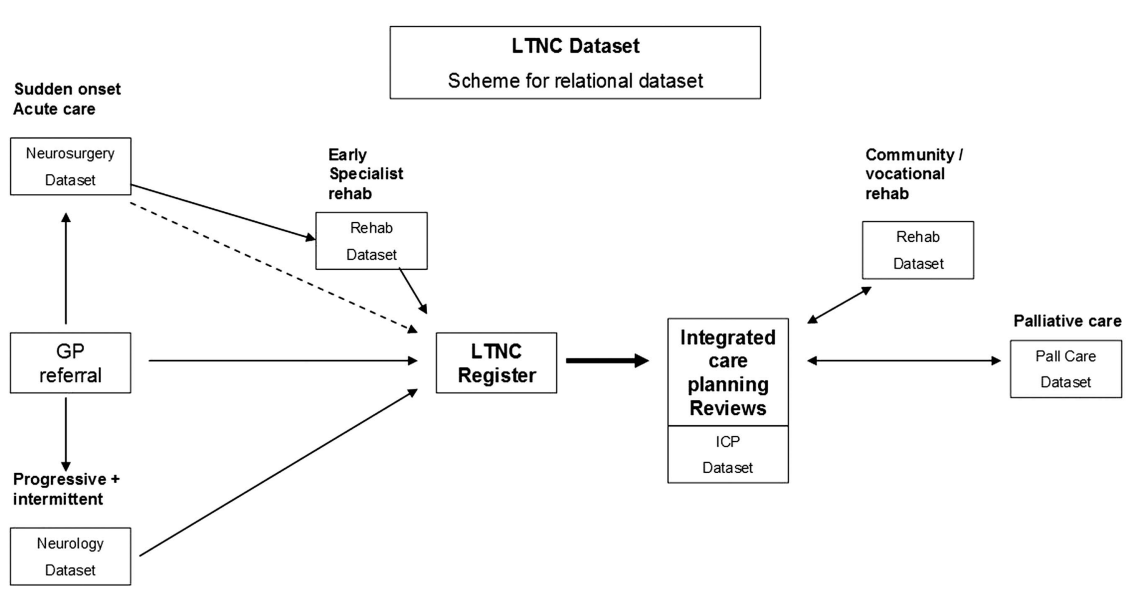

Figure 1 A schematic diagram of the National Service Frameworks (NSF) for long-term neurological conditions (LTNC) care pathway and quality requirements (QRs). (A) The 'fish diagram' illustrates how the different QRs of the NSF fit along the care pathway. The cross-sectional diagram illustrates the range of services that may be needed by a patient with complex needs ${ }^{14}$ (reproduced with permission from Professor LT-S). (B) The overall scheme of the LTNC dataset. The LTNC dataset is made up of a relational database with seven datasets linked via the patient's identifier (National Health Service (NHS) number) following the overall schema of the LTNC pathway. The LTNC register identifies those patients with complex needs who form the denominator for datasets in the later stages of the pathway (reproduced with permission from Professor LT-S).

- Is there a relationship between 'metness of need' in the critical first 6 months following discharge to the community, and 'outcomes' in terms of carer burden and community integration at 1 year?

\section{METHODS}

\section{Part A: Development of the LTNC register}

The overall scheme of the LTNC dataset is summarised in figure 1B. However, before data could be collected in routine clinical practice, the data collection tools had to be made fit for purpose. We therefore refined the database to include a manageable set of tools to identify patient needs, service inputs and patient outcomes for community-based rehabilitation and support services which could be used to inform integrated care planning, both at an individual and a population level.
Table 1 sets out the core information elements of the LTNC register as defined by the original Dataset Development Group. This core set includes:

- The Neurological Impairment Scale (NIS) as a measure of overall severity of the presenting condition. ${ }^{19}$

- The Needs and Provision Complexity Scale (NPCS) as a measure of needs for health and social care services and the extent to which these needs are met. ${ }^{20}$

- The Northwick Park Dependency Scale (NPDS). ${ }^{21}$

The LTNC Dataset Development Group also highlighted the need for other measures to support the evaluation of long-term outcomes at the level of societal participation, including measures of community reintegration and carer burden, although specific tools were not stipulated.

On the basis of evidence from previous research incorporating the opinions and experience of both service users and professionals, we selected the 
Table 1 LTNC register core dataset

\begin{tabular}{|c|c|c|}
\hline Domain & Data fields & Value list/data description \\
\hline 1. LTNC & Do they have an LTNC? & Yes/no/not sure \\
\hline \multicolumn{3}{|l|}{ If yes: } \\
\hline \multirow{2}{*}{$\begin{array}{l}\text { 1a. Record neurological } \\
\text { condition }\end{array}$} & Diagnosis & ICD-10 and/or read codes \\
\hline & or nature of condition & $\begin{array}{l}\text { Free text to describe neurological condition } \\
\text { if no code exists }\end{array}$ \\
\hline 1b. Long term & $\begin{array}{l}\text { Is the condition likely to have an enduring } \\
\text { effect? }\end{array}$ & Yes/no/not sure \\
\hline 2. Needs for care/support & $\begin{array}{l}\text { Do they have complex needs arising } \\
\text { from the LTNC? }\end{array}$ & Yes/no/not sure \\
\hline \multicolumn{3}{|c|}{ ( } \\
\hline 2a. Record impairment severity & Neurological Impairment Scale & 17-item scores \\
\hline $\begin{array}{l}\text { 2b. Record needs for health and } \\
\text { social care }\end{array}$ & $\begin{array}{l}\text { The Needs \& Provision Complexity Scale } \\
\text { (NPCS-Needs) }\end{array}$ & 15-item scores \\
\hline 3. Need for ICP & $\begin{array}{l}\text { Do they require (and want) integrated } \\
\text { care planning }\end{array}$ & Yes/no/not sure \\
\hline $\begin{array}{l}\text { 4. Person responsible for } \\
\text { registration }\end{array}$ & Name of registering clinician & Name and signature \\
\hline \multicolumn{3}{|l|}{ 5. If yes to 1,2 , and 3} \\
\hline $\begin{array}{l}\text { 5a: Are they having integrated } \\
\text { care planning? }\end{array}$ & When was last ICP review? & Date \\
\hline $\begin{array}{l}5 \mathrm{~b} \text { : Is there a single point of } \\
\text { contact? }\end{array}$ & Named person or post & $\begin{array}{l}\text { Name } \\
\text { Job title/contact details }\end{array}$ \\
\hline
\end{tabular}

Community Integration Questionnaire (CIQ) and the Zarit Carer Burden Interview on the basis that (1) they are widely used, psychometrically robust and applicable in LTNC, (2) they are freely available and not restricted by license and (3) they are easily understood and timely to apply. ${ }^{22-25}$ Importantly, all of these are suitable for completion either by self-report questionnaire or administered at interview by professionals.

\section{Measurement tools included in the dataset}

\section{Neurological Impairment Scale}

The NIS comprises a brief 17-item checklist of the major neurological impairments (motor/sensory loss, cognitive, communication, emotional, behaviour) that make up a complex presentation in people with LTNCs. ${ }^{19}$ Item severity scores range from 0 to 3 to assess the impact of these impairments at a functional level, giving a total score range $0-50$. Originally developed as part of the core minimum dataset alongside the UK Functional Assessment Measure, ${ }^{26}$ the NIS is shown to be a valid and reliable measure of neurological impairment suitable for use across a wide range of neurological conditions. $^{19}$ It forms a part of the UK Rehabilitation Outcomes Collaborative (UKROC) national clinical dataset for specialist rehabilitation services (for further information see http://www.csi.kcl.ac.uk/ukroc.html; accessed 9 January 2014).
The Needs and Provision Complexity Scale

The NPCS is a 15-item measure with six subscales (total score range 0-50) in two principal domains ('Health' and 'Social care'). It is shown to be valid and reliable. ${ }^{27}$ It is designed to be used as a simple tool to evaluate needs for health and social care and to identify gaps in service provision, both at the level of the individual and across populations. ${ }^{20}$ It has two parts:

- 'NPCS-Needs' is completed by the treating clinician(s) to evaluate each patient's needs for health and social care in any given period.

- 'NPCS-Gets' is a mirror-image of the same tool, completed at the end of that period to evaluate the levels of service that have been provided in relation to those needs.

Subtracting NPCS-Needs scores from NPCS-Gets scores provides a measure of 'metness of needs' and a simple costing algorithm provides a generic estimate of the likely cost implications of addressing the unmet needs. $^{20}$ The algorithm can be downloaded from http://www.csi.kcl.ac.uk/npcs.html; accessed 9 January 2014).

\section{The Northwick Park Dependency Scale}

The NPDS is a measure of dependency of the individual on help from others in two main parts ${ }^{21}$ :

- The 'Basic Care Needs' (BCN) section (score range 0-65) comprises 12 items covering the daily activities needed for everyday functioning. These include the 
capacity for both physical performance (NPDS-PD; eg, washing, dressing, toileting, eating and drinking etc) and appropriate cognitive behaviour (NPDS-CB) (eg, communication, safety awareness etc).

- The 'Special Nursing Needs' (SNN) section (score range 0-35) includes seven items indicating the need for nursing care, such as a wound requiring dressings.

The NPDS is now widely used in the UK and has been translated into several languages. It is shown to be psychometrically robust. ${ }^{28}$ It, too, forms a part of the UKROC dataset, where algorithms within the UKROC software translate it into the Barthel Indx ${ }^{29}$ and also into the Northwick Park Care Needs assessment-a directly costable measure of care needs in the community. ${ }^{30}$

\section{Community Integration Questionnaire}

The CIQ is a measure of community integration after traumatic brain injury that is suitable for self-completion by the patient or a carer by proxy. It consists of 15 items with a total score range from 0 to 29 comprising three subscales: (1) home integration (range 0-10), (2) social integration (range $0-12$ ) and (3) productivity $(0-7)$. It was originally designed for including in the US TBI Model Systems dataset. Although not yet formally tested in a wider population of patients with LTNC, the psychometric properties of the CIQ have been well established in the context of brain injury. ${ }^{31} 32$

\section{Zarit Burden Interview}

The Zarit Burden Interview (ZBI) is designed to capture the impact of a caring role on the carer's personal and social well-being. ${ }^{33}$ It consists of 22 items (total score 088). For each item the carer rates how often they are affected by the negative aspects of their caring situation on a scale ranging from 0 (never) to 4 (nearly always). Originally developed in the context of dementia, the ZBI has been used in LTNC and other advanced conditions and is shown to be valid for assessing carer burden in these conditions. ${ }^{34} 35$

\section{Questionnaire administration}

As many of the participants had complex disabilities with cognitive/communication difficulties, three types of media were used to gather data in order to maximise response rate and ensure accessibility. Respondents could choose from the following options:

A. Paper-based postal questionnaire.

B. Web-based survey tool, using Survey Methods software (Survey Methods Inc http://www.surveymethods. com).

C. Questionnaire administered by a researcher at telephone interview.

All questionnaires were piloted prior to use. Wherever possible, follow-up telephone interviews were used to complete missing information from questionnaires, and this provided further feedback to refine the datagathering tools. The changes related to presentation (plain language, font size, etc) and did not affect the structure or content of the measurement instruments.

\section{Part B: Longitudinal cohort study}

In part B, the LTNC dataset was used to monitor a cohort of patients over a 1-year period following discharge from all tertiary specialised inpatient rehabilitation services across the London region.

\section{Participating centres}

Nine 'Level 1' services provide a comprehensive network of tertiary specialist inpatient neurological rehabilitation across the London Region of the UK. They provide specialised rehabilitation for the population of patients with complex needs that are beyond the scope of their local (levels 2 and 3) rehabilitation services (http://www. bsrm.co.uk/index.htm; accessed 9 January 2014). ${ }^{36}$ Patients discharged from these units are therefore likely to have complex needs for ongoing rehabilitation and support services in the community. All nine services participated in recruitment in our study.

\section{Participants}

Recruitment occurred over an 18-month period in 2010-2011. Consecutive inpatients across the nine services, were eligible to participate if they had an LTNC at discharge (ie, a neurological condition that was considered likely by the treating team to have an enduring effect). They were approached for consent by a member of the treating team. This was taken in writing on a standard consent form at least $24 \mathrm{~h}$ after provision of an information sheet, a verbal explanation of the study and the opportunity to ask questions. Where cognitive or communication problems prevented their direct participation a family member or carer was identified to assist (or respond on behalf of) the patient and as the primary point of contact for further questionnaires.

\section{Data collection procedure}

For all consenting patients, their discharge team completed a recruitment form that included:

A. Severity of impairment (NIS);

B. Needs for ongoing services (NPCS-Needs) as rated by their multidisciplinary (MD) team;

C. Whether the patient would be willing to be included in an LTNC register;

D. Details of any community rehabilitation support services to which patients had been referred;

E. Contact details for a named individual to approach for follow-up questionnaires (usually either the patient or a family carer).

Baseline data were recorded by the treating MD team as part of their discharge planning. This approach to shared decision-making in the assessment of needs reduced the potential for clinician bias across different disciplines, as the representation of disciplines within the teams was broadly similar across the nine specialist rehabilitation units. Teams were asked to record the 
NPCS-Needs in relation to services that they reasonably expected the patient to receive, based on the referrals they were making for ongoing support and rehabilitation after discharge, rather than those they might wish for 'in an ideal world'.

This recruitment information was then sent to the research team who contacted the named individual to answer questions/address any concerns and to establish their preferred medium for response (ie, postal questionnaire, web-based survey or telephone interview).

Tools included in the questionnaire were self-report versions of:

A. Dependency (NPDS): including BCN (NPDS-BCN) and SNN (NPDS-SNN);

B. Community integration (CIQ);

C. Carer burden (ZBI) - if the individual had a family (or other informal) carer;

D. Services received (NPCS-Gets) in the past 6-month period-recorded at 6 and 12 months.

Participants were contacted at one, 6 and 12 months after discharge and asked to complete a questionnaire/ interview (the month 1 responses acting as baseline for these self-report measures). A second follow-up call was made if a response had not been received within a fortnight. Up to five attempts were made to reach respondents by telephone before desisting.

\section{Efforts to maximise response rates}

Across the three response phases, paper questionnaires were consistently the most commonly used method (approximately $80-84 \%$ of respondents); $10-13 \%$ responded online and $3-5 \%$ were administered at telephone interview. Postal and online questionnaires were followed up by telephone wherever possible to fill in any missing information. Over the course of the study, a total of 1211 questionnaires were sent and 225 resent; 1607 phone calls were made to achieve the 658 questionnaires received.

\section{Data management and analysis}

Data were entered into a spreadsheet (Microsoft Excel) and after cleaning and validation, were extracted to SPSS (IBM Statistics) V.19 for statistical analysis. Despite the ordinal nature of data, in view of the large sample size and the fact that linear regression modelling used in the latter part of the analysis relies on parametric assumptions, parametric techniques were used throughout with descriptive statistics reported in the form of percentages or means, SDs and range. Non-parametric analyses are available on request from the author, but did not yield different results. In view of the multiple tests, the threshold for significance was set at $\mathrm{p}<0.01$.

The first stage of our analyses included a descriptive analysis of all available respondents at each time point. To determine whether patients would want to use an LTNC register, we examined the proportions who agreed to be included and those who actually responded to our requests for follow-up information on each occasion, as an indication of those most likely to use the register.

We examined the characteristics of patients who responded at each time point in terms of demographics, severity of impairment and needs for services. We looked in particular for any statistical differences between the 'best responder' group (those who responded at all three time points) and the 'non-responders' (who did not respond on any occasion). To identify predictors of the extent of rehabilitation received (NPCS-Gets) at 6 months postdischarge we began with a series of univariate regression analyses including all those who responded at 6 months $(\mathrm{n}=212)$. Specifically we examined which of the following variables (recorded at baseline) individually predicted the overall level of rehabilitation services received within the first 6 months:

A. Demographics (ie, age, gender, marital status, education, ethnicity, diagnosis);

B. Level of impairment-both physical (NIS Physical) and cognitive (NIS Cognitive);

C. Level of dependency-physical (NPDS-PD) and cognitive (NPDS-CB) and total BCN (NPDS-BCN) were entered as separate variables;

D. SNN (NPDS-SNN);

E. Social integration in the community (CIQ).

For the demographic variables, age was treated as continuous and the remaining five were all coded as 'dummy' or categorical variables. Physical and cognitive impairment were treated as separate variables in light of previous studies suggesting that people with 'hidden disabilities' received fewer services. The best individual predictors (ie, only those variables that predicted a statistically significant proportion of variance in univariate regression analyses) were all included in a single stepwise multiple regression analysis to identify the best model.

The second stage of our analysis explored the relationship between patient-reported outcomes and the extent to which an individual's needs for services were met. Here the longitudinal trends for change over successive time periods were the specific focus of interest, so only the 'best responders' (for whom data were available at all three time points) were included.

- Differences between NPCS 'Needs' and 'Gets', and between NPCS-Gets during the first and second 6-month period were tested by paired t tests.

- Discrepancy scores between the needs identified by the treating clinicians at discharge (NPCS-Needs) and services received during the first 6-month period (NPCS-Gets) were calculated on a case-by-case basis as a measure of the extent to which individual needs were met (ie, 'metness of need'='NPCS-Gets' minus 'NPCS needs').

Services provided in the first 6-month period after discharge from inpatient rehabilitation were considered to be particularly critical to support adjustment and (where possible) reablement following newly acquired disability. To examine the relationship between outcome (in terms of community integration and carer burden) at 
12 months and the extent to which individual needs for rehabilitation were met during the first 6 months, discrepancy scores for the NPCS rehabilitation subscale were entered as predictor values in a longitudinal linear regression analysis. We examined outcomes, (CIQ and $\mathrm{ZBI}$ ) in comparison with 'metness of need' in the rehabilitation subscale of the NPCS. We also dichotomised patients into those whose rehabilitation needs were met or exceeded in the first 6 months (Gets minus Needs $\geq 0$ ) and those who had unmet needs (Gets minus Needs $<0)$. For this analysis the variables entered into the model were selected on a priori theoretical grounds. Although we expected the level of community integration to be negatively affected by physical and cognitive dependency, we hypothesised that patients whose needs for rehabilitation and support were met would achieve better integration than those with unmet needs.
RESULTS

Recruitment and response rates

Out of a total of 576 admissions, 499 patients were assessed as eligible for inclusion in the study, because they had an LTNC that was likely to have an enduring effect. They were approached by the clinical teams for permission to include them in the study, of which 428 (92\%) were recruited. Across the nine units just $8 \%$ of those approached declined to participate in the study. Some centres were notably more successful at recruiting than others. Highest recruitment rates ( $>93 \%$ of admissions) were seen where a single individual (eg, a consultant or a dedicated recruitment officer) took responsibility for recruiting all participants within that unit. Lower rates (approximately $2 / 3$ of admissions overall) were achieved where recruitment was left to one of several members of the team (eg, a keyworker or one
Figure 2 Recruitment and participation pathway.

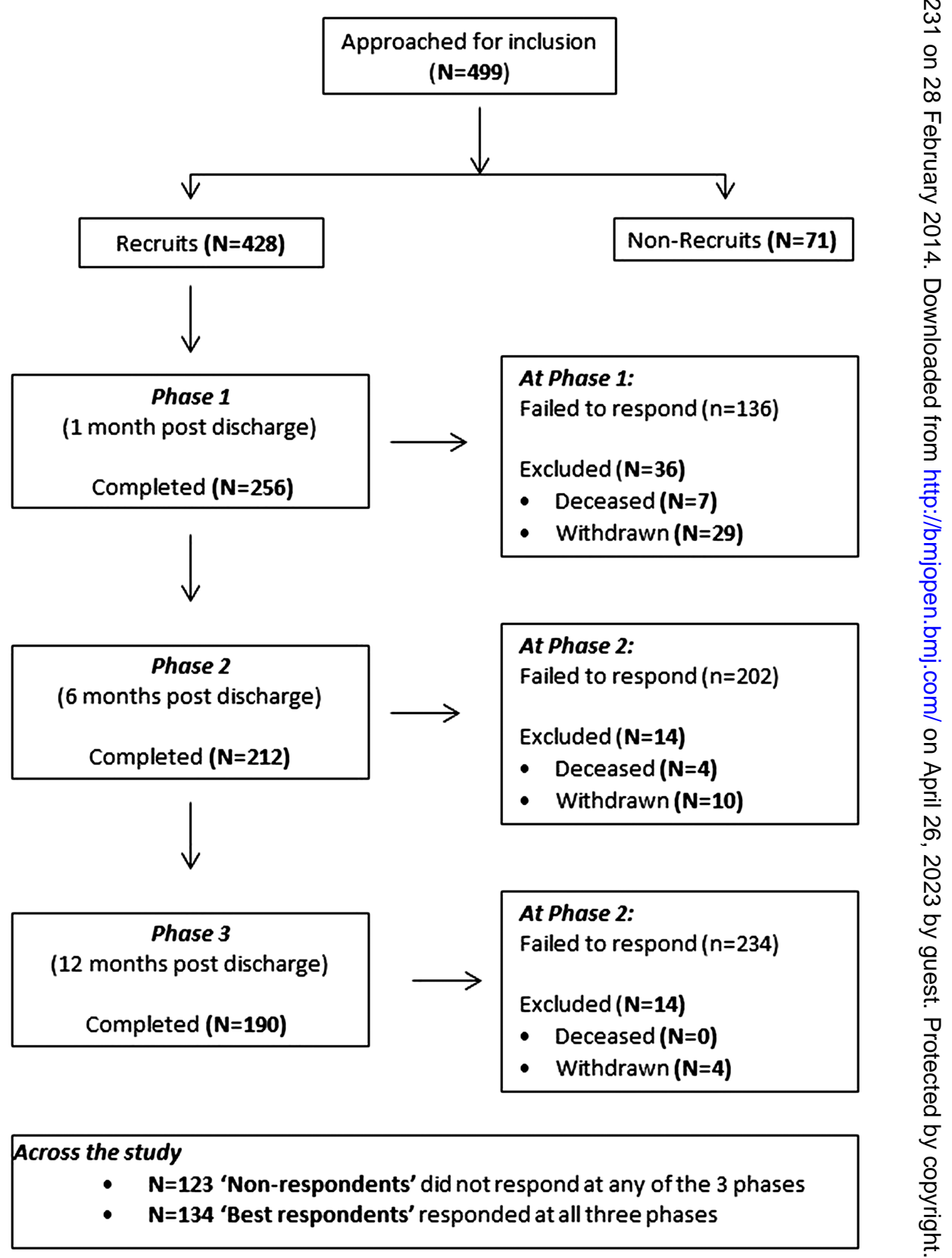


Table 2 Characteristics of the 428 patients recruited, the 'best responder' $(n=134)$ and the non-responder ( $n=123)$ group

\begin{tabular}{|c|c|c|c|c|c|c|c|}
\hline \multirow[b]{2}{*}{ Variables } & \multicolumn{2}{|c|}{$\begin{array}{l}\text { Recruited sample } \\
\mathrm{N}=428\end{array}$} & \multicolumn{2}{|c|}{$\begin{array}{l}\text { Best responders } \\
\mathrm{N}=134\end{array}$} & \multicolumn{2}{|c|}{$\begin{array}{l}\text { Non-responders } \\
\mathrm{N}=123\end{array}$} & \multirow{2}{*}{$\begin{array}{l}\chi^{2} \text { Test }^{\star} \\
\text { p Value }\end{array}$} \\
\hline & $\mathbf{N}$ & Per cent & $\mathbf{N}$ & Per cent & $\mathbf{N}$ & Per cent & \\
\hline \multicolumn{8}{|l|}{ Gender } \\
\hline Male & 270 & $(63.1)$ & 86 & (64.2) & 80 & $(65.0)$ & 0.90 \\
\hline Female & 158 & (36.9) & 48 & (35.8) & 43 & (35.0) & \\
\hline \multicolumn{8}{|l|}{ Diagnosis } \\
\hline Brain injury & 315 & $(73.6)$ & 97 & $(72.8)$ & 85 & (69.1) & 0.35 \\
\hline Stroke/SAH ${ }^{*}$ & 212 & $(49.5)$ & 70 & (52.2) & 57 & (46.3) & \\
\hline $\mathrm{TBI}^{*}$ & 63 & (14.7) & 16 & (11.9) & 18 & (14.6) & \\
\hline Other $\mathrm{ABI} \mathrm{I}^{*}$ & 40 & (9.3) & 11 & (8.2) & 10 & $(8.1)$ & \\
\hline Spinal cord injury & 38 & (8.9) & 8 & $(6.0)$ & 11 & (8.9) & \\
\hline Peripheral neuropathy & 26 & $(6.1)$ & 8 & $(6.0)$ & 9 & (7.3) & \\
\hline Progressive LTNC & 21 & $(4.9)$ & 5 & (3.7) & 10 & $(8.1)$ & \\
\hline Other & 27 & (6.3) & 16 & (11.9) & 7 & (5.7) & \\
\hline Missing & 1 & $(0.2)$ & 0 & (0) & 1 & $(0.8)$ & \\
\hline \multicolumn{8}{|l|}{ Discharge destination } \\
\hline Home & 333 & $(77.8)$ & 115 & $(85.8)$ & 89 & (72.4) & 0.009 \\
\hline Nursing home & 51 & (11.9) & 9 & $(6.7)$ & 19 & (15.4) & 0.03 \\
\hline On-going rehabilitation & 18 & $(4.2)$ & 6 & $(4.5)$ & 5 & $(4.1)$ & 1.0 \\
\hline Hospital & 4 & $(1.0)$ & 2 & $(1.5)$ & 1 & $(0.8)$ & 1.0 \\
\hline Other & 19 & $(4.4)$ & 2 & (1.5) & 9 & (7.3) & 0.03 \\
\hline \multicolumn{8}{|c|}{ Referred to ongoing rehabilitation } \\
\hline Yes & 378 & (88.3) & 124 & $(92.5)$ & 110 & $(89.4)$ & 0.33 \\
\hline No & 41 & $(9.6)$ & 7 & $(5.2)$ & 11 & (8.9) & \\
\hline Not answered & 9 & $(2.1)$ & 3 & $(2.2)$ & 2 & $(1.6)$ & \\
\hline \multicolumn{8}{|c|}{ Permission to include on the register } \\
\hline Yes & 322 & $(75.2)$ & 108 & $(80.6)$ & 90 & $(73.2)$ & 0.23 \\
\hline No & 13 & $(3.0)$ & 3 & (2.2) & 7 & $(5.7)$ & \\
\hline Not answered & 93 & $(21.7)$ & 23 & $(17.2)$ & 26 & $(21.1)$ & \\
\hline At recruitment & Mean & SD & Mean & SD & Mean & SD & $\begin{array}{l}\text { t Test }{ }^{\star} \\
\text { p value }\end{array}$ \\
\hline \multicolumn{8}{|l|}{ Age } \\
\hline Years & 49.1 & $(15.2)$ & 50.2 & $(14.0)$ & 47.8 & $(15.9)$ & 0.19 \\
\hline \multicolumn{8}{|l|}{ Neurological impairment } \\
\hline NIS-Motor & 8.1 & $(5.1)$ & 8.3 & $(5.0)$ & 8.9 & $(5.4)$ & 0.36 \\
\hline NIS-Cognitive & 4.4 & (3.1) & 4.4 & (3.2) & 4.8 & (3.0) & 0.34 \\
\hline Total & 12.8 & $(6.4)$ & 13.1 & $(6.4)$ & 13.9 & $(6.7)$ & 0.37 \\
\hline \multicolumn{8}{|c|}{ Needs for health and social care } \\
\hline NPCS Health & 11.5 & $(4.3)$ & 11.4 & $(4.2)$ & 11.9 & $(4.5)$ & 0.31 \\
\hline NPCS-Social support & 6.2 & (4.3) & 5.6 & $(4.0)$ & 6.7 & $(4.8)$ & 0.04 \\
\hline NPCS-Total & 17.7 & $(7.8)$ & 17.0 & (7.6) & 18.7 & (8.4) & 0.09 \\
\hline
\end{tabular}

*Difference between best responders and non-responders.

Significant differences are highlighted in bold.

LTNC, long-term neurological condition; NIS, Neurological Impairment Scale; NPCS, Needs and Provision Complexity Scale.

of the junior medical staff), who were less familiar with the study.

The participation and attrition rates throughout the study are displayed in figure 2 . The characteristics of the 428 patients recruited are shown in table 2 .

Do patients want to be entered on an LTNC register, and which patients might be most likely to participate?

Consent to participate in the study questionnaires did not necessarily mean that individuals would be willing to have their details included in a register. Three-quarters of the recruited group $(\mathrm{n}=322(75 \%))$ indicated, at discharge from hospital, that they were willing to be included in a pilot LTNC register. On the other hand only $13(3 \%)$ declined. The remaining 93 (22\%) did not answer the question mostly due to a failure on the part of the clinician to ask. However, only a proportion of the recruits actually responded to questionnaires when subsequently approached in the community. At 1-month postdischarge, 59\% responded; at 6 months $49 \%$ and at 12 months just $44 \%$. The response across the three time periods was not consistent: 123 (29\%) did not respond to a questionnaire in any of the phases; $20-21 \%$ responded to one or two phases and just $134(31 \%)$ responded to all 
three phases. This latter group of 'best responders' was considered to be the group of patients most likely to engage in follow-up using an LTNC register, but interestingly there was no sigificant difference between the 'best responders' and the 'non-responders' in terms of their expressed willingness to be included in the register.

\section{Characteristics of the responding patients across the three phases}

Respondents were similar at each phase in terms of gender ratio, age, marital status and educational level. The only significant trend over time was a greater attrition for non-white British participants, reflected in the loss of $39 \%$ of black and $49 \%$ Asian/other participants as compared with only $18 \%$ attrition for white participants. The 'best responders' were more likely to have been discharged home than the non-responders, a greater proportion of whom were in nursing home or other residential care. Otherwise there were no significant differences in demographics between these two groups, and they had similar levels of impairment and needs for services at recruitment (see table 2).

\section{The extent to which needs were and were not met}

Table 3 shows descriptive statistics for measures of impairment, needs, inputs and outcome across the three follow-up phases. Again there was no difference between the groups responding at each time period with respect to their severity of impairment (total NIS score) or need for services (NPCS-Needs), nor with respect to their outcomes in terms of dependency (NPDS) integration (CIQ) or carer burden (ZBI).

The level of services received during the first 6 months was significantly lower than the needs identified at discharge for both healthcare (mean difference $1.8(95 \%$ CI 1.1 to 2.4$) \mathrm{t}=5.1, \mathrm{p}<0.001)$ and social care (mean difference 1.7 (95\% CI 1.1 to 2.2$) \mathrm{t}=5.9$, $\mathrm{p}<0.001)$. There was a modest overall decline in the levels of both health and social support services during the second 6 months, even though the levels of dependency, community integration and carer burden remained similar. However, this could simply have been due to differences in the best responder group at 6 and 12 months. Therefore, a paired analysis was conducted for just the best responder group, who responded on all three occasions. Although these best responders $(n=134)$ formed less than one-third of the total population, there was no evidence that they differed in any significant respect from the recruited population (see tables 2 and 3 ).

Table 4 shows a more detailed evaluation of the met and unmet needs (as measured by the NPCS) for this 'best responder group during the first 6 months. It also shows the change in levels of service provided during the second 6-month period, and the change in outcomes across the three time points of the study. As recorded elsewhere for the full cohort, ${ }^{20}{ }^{37}$ this subgroup analysis confirms significant levels of unmet needs with respect to rehabilitation, social support and equipment provision during the first critical 6 months following discharge. ${ }^{20}{ }^{37}$ It also records a significant decline in service provision between months 6 and 12, despite continuing high and unchanging levels of dependency and carer burden. On the other hand, needs for medical and nursing inputs, personal care and accommodation were well met. The level of community integration appears to decrease slightly at 6 months and then return to baseline levels at 12 months.

However, within the study sample there is clearly significant variation, both with respect to the level of services provided and outcome. It is therefore pertinent to examine what predicts the levels of service provision, especially during the first critical 6 months after discharge to the community, and whether there is a relationship between 'metness of needs' and outcome.

\section{What predicts the level of services received in the first 6 months after discharge?}

The univariate regression analyses showed that none of the demographic variables (age, gender, ethnicity, marital status, education, diagnosis) nor carer burden (ZBI) recorded at baseline were significantly related to the levels of service received (total NPCS-Gets) at 6 months. The baseline measures of impairment (NIS), dependency (NPDS), nursing needs (NPDS-SNN) and community integration (CIQ), however, all predicted a significant proportion of the variance, as well as demonstrating significant inter-relationships as shown in table 5 .

Results of a stepwise regression analysis that included the significant predictors from univariate regression analyses are presented in table 6 . In both the univariate analyses and in the stepwise model dependency (NPDS-BCN) was the best single predictor accounting for $33 \%$ of the model variance. The addition of motor and cognitive impairment (as measured by the NIS subscales at recruitment) improved the predictive ability of the stepwise model by small but significant increments to a total $\mathrm{R}^{2}$ of $40 \%$. Community integration and $\mathrm{SNN}$ did not add significantly to the prediction of variance and so were excluded by the stepwise regression.

Is there a relationship between 'metness of need' in the first critical 6 months and outcome in terms of community integration and carer burden at 12 months?

We wished to determine whether the extent to which rehabilitation needs were met impacted on community integration and carer burden at 12 months, over and above any relationship between these outcomes and dependency. Taking community integration scores (CIQ) at 12 months as the dependent variable, a stepwise regression was carried out using physical dependency (NPDS-PD) and cognitive dependency (NPDS-CB) at baseline, and 'metness' of rehabilitation needs at 6 months as independent variables. This revealed that $31 \%$ of the variance in community integration could be 
Table 3 Descriptive statistics for measures of impairment severity (NIS, motor, cognitive), service needs (NPCS-Needs), service inputs (NPCS-Gets) and patient-reported outcome (CIQ, ZBI) across the three phases after discharge and for the group that responded at all three phases

\begin{tabular}{|c|c|c|c|c|}
\hline Time & $\begin{array}{l}\text { Phase } 1 \\
\text { 1-month } \\
\text { postdischarge } \\
\mathrm{N}=256\end{array}$ & $\begin{array}{l}\text { Phase } 2 \\
6 \text {-month } \\
\text { postdischarge } \\
\mathrm{N}=212\end{array}$ & $\begin{array}{l}\text { Phase } 3 \\
\text { 12-month } \\
\text { postdischarge } \\
\mathrm{N}=190\end{array}$ & $\begin{array}{l}\text { 'Best responders' at } \\
\text { recruitment and } \\
\text { phase } 3 \mathrm{~N}=134\end{array}$ \\
\hline Measure & Mean (SD) & Mean (SD) & Mean (SD) & Mean (SD) \\
\hline (scoring range) & $\begin{array}{l}\text { Range (minimum- } \\
\text { maximum) }\end{array}$ & $\begin{array}{l}\text { Range (minimum- } \\
\text { maximum) }\end{array}$ & $\begin{array}{l}\text { Range (minimum- } \\
\text { maximum) }\end{array}$ & $\begin{array}{l}\text { Range (minimum- } \\
\text { maximum) }\end{array}$ \\
\hline \multicolumn{5}{|l|}{$\begin{array}{l}\text { At recruitment: } \\
\text { Impairment }\end{array}$} \\
\hline \multicolumn{5}{|l|}{ Physical } \\
\hline NIS-Motor & $7.8(4.9)$ & $7.9(5.1)$ & $8.1(5.0)$ & $8.3(5.0)$ \\
\hline $\begin{array}{l}\text { (range 0-26) } \\
\text { Cognitive }\end{array}$ & $0-25$ & $0-25$ & $0-25$ & $0-25$ \\
\hline NIS cognitive & $4.3(3.1)$ & $4.5(3.2)$ & $4.2(3.0)$ & $4.4(3.2)$ \\
\hline (range 0-21) & $0-14$ & $0-13$ & $0-13$ & $0-13$ \\
\hline NIS total & $12.4(6.4)$ & $12.7(6.5)$ & $12.7(6.2)$ & $13.1(6.4)$ \\
\hline$(0-50)$ & $1-31$ & $1-31$ & $1-31$ & $1-31$ \\
\hline \multicolumn{5}{|c|}{$\begin{array}{l}\text { Level of services required (NPCS-Needs) } \\
\text { Health and care }\end{array}$} \\
\hline NPCS-Health Needs & $11.3(4.1)$ & $11.4(4.2)$ & $11.2(4.2)$ & $11.4(4.2)$ \\
\hline $\begin{array}{l}\text { (Range 0-25) } \\
\text { Social support }\end{array}$ & $0-21$ & $0-20$ & $0-21$ & $0-20$ \\
\hline NPCS-Social Needs & $5.7(4.0)$ & $6.1(4.2)$ & $5.8(4.0)$ & $5.6(4.0)$ \\
\hline (range 0-25) & $0-19$ & $0-19$ & $0-19$ & $0-19$ \\
\hline Total NPCS Needs & $17.0(7.5)$ & $17.5(7.7)$ & $17.0(7.6)$ & $17.0(7.6)$ \\
\hline$(0-50)$ & $0-36$ & $1-36$ & $0-36$ & $0-36$ \\
\hline \multicolumn{5}{|l|}{$\begin{array}{l}\text { Service provision } \\
\text { Health and care }\end{array}$} \\
\hline $\begin{array}{l}\text { NPCS-Health Gets } \\
(0-25) \\
\text { Social support }\end{array}$ & Not applicable & $\begin{array}{l}9.4(4.7) \\
0-20\end{array}$ & $\begin{array}{l}8.5(4.8) \\
0-21\end{array}$ & $\begin{array}{l}8.4(4.9) \\
0-21\end{array}$ \\
\hline $\begin{array}{l}\text { NPCS-Social Gets } \\
(0-25)\end{array}$ & Not applicable & $\begin{array}{l}4.6(3.5) \\
0-15\end{array}$ & $\begin{array}{l}3.8(3.1) \\
0-15\end{array}$ & $\begin{array}{l}3.8(3.2) \\
0-15\end{array}$ \\
\hline $\begin{array}{l}\text { Total NPCS-Gets } \\
(0-50)\end{array}$ & Not applicable & $\begin{array}{l}14.0(7.1) \\
0-29\end{array}$ & $\begin{array}{l}12.5(7.1) \\
0-34\end{array}$ & $\begin{array}{l}12.4(7.2) \\
0-34\end{array}$ \\
\hline \multicolumn{5}{|l|}{ Outcome measures } \\
\hline NPDS & 12.7 (13.9) & $12.2(13.8)$ & $11.2(13.5)$ & $11.4(13.5)$ \\
\hline $\begin{array}{l}(0-100) \\
\text { Integration }\end{array}$ & $0-66$ & $0-61$ & $0-60$ & $0-60$ \\
\hline $\mathrm{CIQ}$ & $12.1(4.9)$ & $11.0(5.7)$ & $12.3(5.7)$ & $12.3(5.8)$ \\
\hline $\begin{array}{l}(0-29) \\
\text { Carer burden }\end{array}$ & $0-26$ & $0-27$ & $0-27$ & $0-27$ \\
\hline ZBI & $24.4(16.7)$ & $24.4(17.5)$ & 25.5 (18.9) & 26.9 (18.6) \\
\hline$(0-88)$ & $0-82$ & $0-82$ & $0-88$ & $0-84$ \\
\hline
\end{tabular}

CIQ, Community Integration Questionnaire; NIS, Neurological Impairment Scale; NPCS, Needs and Provision Complexity Scale; ZBI, Zarit

Care Burden Interview.

explained by physical and cognitive dependency; the more dependent patients being less well integrated at 12 months. The extent to which their rehabilitation needs had been met was positively correlated with dependency at baseline $(\mathrm{r}=0.20, \mathrm{p}=0.03)$, and added only $2 \%$ to the predictor model, so that together they explained $33 \%$ of the variance. However, the relationship was not in the expected direction. Patients $(\mathrm{n}=31)$ who received rehabilitation services that met or exceeded the levels of need predicted at discharge showed significantly lower gains in CIQ than those for whom provision did not meet their predicted need $(\mathrm{n}=71)$ : mean difference $2.6 \quad(95 \%$ CI 0.9 to 4.3 , $\mathrm{p}=0.003)$. 
Table 4 Best-responder population ( $n=134$ ): descriptive statistics and significant differences in needs, inputs and outcomes at baseline, 6 and 12 months

\begin{tabular}{|c|c|c|c|c|c|c|c|c|c|c|c|c|c|}
\hline \multirow[b]{2}{*}{ NPCS } & \multirow[b]{2}{*}{ Missir } & \multirow[b]{2}{*}{$\begin{array}{l}\text { Baseline } \\
\text { Mean } \\
\text { (SD) } \\
\text { Needs }\end{array}$} & \multirow[b]{2}{*}{$\begin{array}{l}6 \text { Months } \\
\text { Mean (SD) } \\
\text { Gets at } \\
6 \text { months }\end{array}$} & \multicolumn{4}{|c|}{$\begin{array}{l}\text { Difference between needs identified at } \\
\text { discharge and levels of service received } \\
\text { during the first } 6 \text { months }\end{array}$} & \multirow[b]{2}{*}{ Missing } & \multirow[b]{2}{*}{$\begin{array}{l}12 \text { Months } \\
\text { Mean (SD) } \\
\text { Gets at } \\
12 \text { months }\end{array}$} & \multicolumn{4}{|c|}{$\begin{array}{l}\text { Difference in level of services received } \\
\text { during the } 1 \text { st and } 2 \text { nd } 6-\text { month periods }\end{array}$} \\
\hline & & & & $\begin{array}{l}\text { Mean } \\
\text { difference }\end{array}$ & $95 \% \mathrm{Cl}$ & $\begin{array}{l}p \\
\text { Value }\end{array}$ & $\begin{array}{l}\text { Effect } \\
\text { size }^{*}\end{array}$ & & & $\begin{array}{l}\text { Mean } \\
\text { difference }\end{array}$ & $95 \% \mathrm{Cl}$ & $\begin{array}{l}p \\
\text { Value }\end{array}$ & $\begin{array}{l}\text { Effect } \\
\text { size }^{\star}\end{array}$ \\
\hline \multicolumn{14}{|c|}{ Health and personal care domain } \\
\hline Health & 2 & $2.3(1.5)$ & $2.4(1.7)$ & 0.04 & -0.3 to 0.4 & 0.81 & 0.03 & 2 & $2.2(1.6)$ & -0.1 & -0.4 to 0.1 & 0.25 & 0.06 \\
\hline Personal care & 7 & $3.7(2.7)$ & $3.6(2.6)$ & 0.02 & -0.4 to 0.5 & 0.92 & 0.01 & 8 & $3.3(2.6)$ & -0.4 & -0.7 to 0.1 & 0.02 & 0.15 \\
\hline Rehabilitation & 5 & $5.3(1.9)$ & $3.6(2.0)$ & -1.7 & -2.1 to -1.3 & $<0.001$ & 0.89 & 8 & $2.9(2.2)$ & -0.8 & -1.2 to -0.5 & $<0.001$ & 0.40 \\
\hline Total & 13 & $11.4(4.2)$ & $9.5(4.7)$ & -1.6 & -2.5 to -0.8 & $<0.001$ & 0.38 & 16 & $8.4(4.9)$ & -1.4 & -2.0 to -0.8 & $<0.001$ & 0.30 \\
\hline \multicolumn{14}{|c|}{ Social care and support domain } \\
\hline Social support & 12 & $2.8(2.6)$ & $1.6(2.0)$ & -1.2 & -1.7 to -0.7 & $<0.001$ & 0.46 & 15 & $1.2(1.7)$ & -0.4 & -0.7 to -0.1 & 0.005 & 0.20 \\
\hline Equipment & 4 & $1.2(0.9)$ & $0.8(0.8)$ & -0.4 & -0.6 to -0.2 & $<0.001$ & 0.44 & 6 & $0.6(0.8)$ & -0.2 & -0.4 to -0.1 & 0.004 & 0.25 \\
\hline Accommodation & 2 & $1.6(1.9)$ & $1.8(2.0)$ & 0.2 & -0.1 to 0.5 & 0.16 & 0.11 & 2 & $1.9(1.9)$ & 0.1 & -0.1 to 0.4 & 0.23 & 0.05 \\
\hline Total & 14 & $5.6(4.0)$ & $4.1(3.2)$ & -1.5 & -2.2 to -0.9 & 0.07 & 0.37 & 18 & $3.8(3.2)$ & -0.4 & -0.8 to 0.0 & 0.06 & 0.13 \\
\hline \multicolumn{14}{|c|}{ Total needs and provision } \\
\hline Total & 22 & $16.8(7.6)$ & $13.7(6.9)$ & -3.1 & -4.3 to -1.8 & $<0.001$ & 0.41 & 29 & $12.1(7.1)$ & -1.9 & -2.7 to -1.1 & $<0.001$ & 0.27 \\
\hline \multicolumn{14}{|c|}{ Outcome measures (total scores) } \\
\hline $\begin{array}{l}\text { Dependency } \\
\text { (NPDS) }\end{array}$ & 0 & $12.8(13.3)$ & $12.4(14.4)$ & -0.4 & -1.6 to 0.8 & 0.51 & 0.03 & 0 & $11.4(13.5)$ & -1.0 & -1.9 to 0.0 & 0.05 & 0.07 \\
\hline $\begin{array}{l}\text { Integration } \\
(\mathrm{CIQ})\end{array}$ & 24 & $12.3(4.9)$ & $11.4(5.6)$ & -1.0 & -1.7 to 0.2 & 0.01 & 0.22 & 21 & $12.4(5.7)$ & 0.9 & -0.4 to 1.5 & 0.002 & 0.16 \\
\hline $\begin{array}{l}\text { Carer burden } \\
\text { (ZBI) }\end{array}$ & $53 \dagger$ & $23.7(17.1)$ & $24.1(17.2)$ & 0.4 & -2.1 to 2.9 & 0.75 & 0.06 & $55 \dagger$ & $25.3(18.1)$ & 1.5 & -0.5 to 3.5 & 0.15 & 0.09 \\
\hline
\end{tabular}

${ }^{*}$ Effect sizes for the first 6 months were calculated as mean difference/SD baseline and for the second 6 months: mean difference/SD at 6 months

tCarer burden scores were only recorded where a family carer was involved.

CIQ, Community Integration Questionnaire; NPCS, Needs and Provision Complexity Scale; NPDS, Northwick Park Dependency Scale; ZBI, Zarit Care Burden Interview.

Significant $\mathrm{p}$ values (tested by paired t tests) are highlighted in bold. 
Table 5 Correlation matrix of predictor variables of services received (NPCS-Gets) at 6 month $(n=212)$

\begin{tabular}{|c|c|c|c|c|c|c|}
\hline Variable & $\begin{array}{l}\text { NPCS-Gets } \\
6 \text { months }\end{array}$ & NIS-Motor & NIS-Cognitive & NPDS-Physical & NPDS-Cog/Behav & SNN \\
\hline NIS-Motor & $0.44^{\star \star}$ & & & & & \\
\hline NIS-Cognitive & $0.38^{\star \star}$ & $0.15^{\star}$ & & & & \\
\hline NPDS-Physical & $0.58^{\star \star}$ & $0.67^{* \star}$ & $0.36^{\star \star}$ & & & \\
\hline NPDS-Cog/Behav & $0.45^{\star \star}$ & $0.20^{* *}$ & $0.62^{\star \star}$ & & & \\
\hline NPDS-BCN & $0.62^{\star \star}$ & $0.62^{\star \star}$ & $0.45^{\star \star}$ & $0.98^{\star *}$ & & \\
\hline NPDS-SNN & $0.45^{\star \star}$ & $0.23^{\star *}$ & 0.11 & $0.35^{\star \star}$ & $0.22^{\star \star}$ & \\
\hline $\mathrm{CIQ}$ & $-0.45^{\star \star}$ & $-0.48^{\star *}$ & -0.40 & $-0.57^{\star \star}$ & $-0.46^{\star \star}$ & -0.15 \\
\hline ZBI & $0.30^{\star \star}$ & 0.08 & $0.34^{\star \star}$ & $0.20^{\star}$ & $0.36^{\star \star}$ & -0.00 \\
\hline
\end{tabular}

A similar stepwise regression was performed for the dependent variable carer burden (ZBI) at 12 months, entering physical dependency (NPDS-PD) and cognitive dependency (NPDS-CB) at baseline, and 'metness' of rehabilitation needs at 6 months as independent variables. Here only cognitive dependency remained in the final model, predicting $12 \%$ of the variance in carer burden, with the other two variables not improving the model significantly. There was no significant difference observed in carer burden scores between patients with 'met' and 'unmet' needs for rehabilitation.

\section{DISCUSSION}

This paper describes further development of the LTNC dataset to identify a manageable set of tools suitable for use in routine practice to measure needs, inputs and outcomes from community-based rehabilitation and support services. In a cohort of nearly 500 patients with complex needs arising from an LTNC, the large majority were willing in principle to be registered and have their data included in the dataset. However, in practice, only a minority (less than one-third) responded regularly when asked to provide information about their ongoing needs and the level of services received. Reasons for attrition were mostly unknown since, for ethical reasons, all participants had the right to withdraw at any stage without any explanation. The 'best responders' included a higher proportion of white British patients, and were more likely to be at home, but were not otherwise distinguishable from the non-responder group, in terms of severity of impairment, disability or needs for services.

The level of attrition observed here was not dissimilar from other series. A similar loss to follow-up of registered brain-injured patients has been noted in a number of other studies. Corrigan $e t a l^{38}$ analysed three USA datasets covering several thousand adults with traumatic brain injury, of whom only $58 \%$ could be followed up 1-year postinjury. In the $\mathrm{UK}$, Wade $e t a l^{99}$ reported a similar rate of attrition ( $59 \%$ at 6 months) and highlighted the difficulties of follow-up in brain-injured patients, which include itinerancy, and lack of motivation or ability to respond. The higher proportion of non-respondents in nursing homes or other inpatient settings observed in our study is likely to reflect (1) the fact that many were unable to respond for themselves and (2) the difficulty of identifying someone willing and able to respond on their behalf in these settings. Culturally related psychosocial factors, such as cultural mistrust and perceptions of exploitation in medical research by minority groups, are

Table 6 Stepwise regression analyses of best individual predictor variables of services received (NPCS-Gets) during the first 6 months after discharge

\begin{tabular}{|c|c|c|c|c|c|}
\hline Stepwise Models & $\boldsymbol{\beta}$ & $\mathrm{Cl}(95 \%)$ & p Value & $\mathbf{R}^{2}$ & $\Delta \mathrm{R}^{2}$ \\
\hline $\begin{array}{l}\text { Model } 1 \\
\text { NPDS-BCN }\end{array}$ & 0.34 & 0.26 to 0.43 & 0.001 & 0.33 & - \\
\hline $\begin{array}{l}\text { Model } 2 \\
\text { NPDS-BCN } \\
\text { NIS-Motor }\end{array}$ & $\begin{array}{l}0.23 \\
0.37\end{array}$ & $\begin{array}{l}0.12 \text { to } 0.34 \\
0.13 \text { to } 0.60\end{array}$ & $\begin{array}{l}0.001 \\
0.001\end{array}$ & 0.38 & 0.05 \\
\hline $\begin{array}{l}\text { Model } 3 \\
\text { NPDS-BCN } \\
\text { NIS-Motor } \\
\text { NIS-Cognitive }\end{array}$ & $\begin{array}{l}0.18 \\
0.40 \\
0.34\end{array}$ & $\begin{array}{l}0.06 \text { to } 0.30 \\
0.17 \text { to } 0.63 \\
0.02 \text { to } 0.67\end{array}$ & $\begin{array}{l}0.001 \\
0.001 \\
0.001\end{array}$ & 0.40 & 0.02 \\
\hline
\end{tabular}

BCN, Basic Care Needs; NPDS, Northwick Park Dependency Scale; SNN, Special Nursing Needs. 
known to affect research participation and may be associated with attrition from registers more generally by people from black and ethnic minority groups when compared with other populations. ${ }^{384041}$

Whatever the reasons for it, the high attrition rate among those participants who agreed to participate suggests that a register based on postal/telephone follow-up will be labour intensive and might fail to engage a significant proportion of the most vulnerable patients. In clinical practice, integrated care planning reviews most commonly involve face-to-face meetings with the patient and carer. In the authors' view, this is likely to offer a more effective route for data collection for the register. The NPCS provides a simple and practical tool to capture met and unmet needs in this context, and so may assist clinical teams to identify and address any gaps in service provision at either an individual or an organisational level.

Longitudinal study of the best responder group revealed that they changed little in terms of dependency or community integration during the year following discharge from inpatient specialist rehabilitation, and the burden on their carers also remained stable. In common with the larger cohort, they had significant unmet needs for health and social care services-particularly with respect to rehabilitation, social worker support and provision of specialist equipment. ${ }^{20}$ Physical disability was the best single predictor of services received, followed by cognitive/behavioural disability. In contrast to some other studies there was no strong evidence that those with hidden disabilities were less able to access services than those with physical disability. ${ }^{17}$ However, this may be due to the targeted efforts of the inpatient teams to set up services for them following discharge to the community.

We had expected to demonstrate that patients whose needs for community-based rehabilitation were met had better outcomes in terms of functional independence and community integration, with reduced burden on carers. In fact, if anything we showed that their outcomes were worse. Over and above the relationship with physical and cognitive dependency, patients whose rehabilitation needs were met or exceeded during the initial 6 months had made fewer gains in integration at 12 months postdischarge than those with unmet needs. While counter-intuitive, on a clinical level this paradoxical finding is not entirely surprising. The most likely explanation reflects the 'inverse therapy rule', which is simply that in a health culture where resources are limited, services will be focused on those patients with the severest problems who have the greatest need. ${ }^{42}$ Professionals are likely to withdraw sooner from those patients who improve quickly over time and meet their goals early on in the programme, and to target their resources on those who continue to require their help.

A weakness of this study was that needs were not re-assessed at each time point, so we cannot determine whether under provision of services with respect to predicted needs reflected unmet or changing levels of need. This argues for the importance of continued review in future studies, measuring both needs and inputs to capture change over time. The NPCS provides a simple practical means to do this.

Other weaknesses are as follows:

- While the cohort was large it only included patients from tertiary rehabilitation services in the greater London metropolitan area and experiences might be different in other parts of the UK particularly rural regions.

- The high attrition rates in the longitudinal study are discussed above. While there were no discernable differences between reponders and non-responders on any demographic variables, except for ethnicity and discharge destination, non-response bias is likely to be present. Consequently it is uncertain how well the findings of this study might apply to the broader population of people with LTNCs.

- We carried out more than 30 statistical tests, which carries the risk of type I error rate inflation, and we dealt with this by setting the $p$ value for significance at 0.01 . We could have set a more stringent $\mathrm{p}$ value at 0.001 for an overall $\alpha$ level of 0.05 - the Bonferroni method. However, this can increase the likelihood of type II errors, so that truly important differences are deemed non-significant, and create more problems than it solves. ${ }^{43}$ The Bonferroni method is concerned with the general null hypothesis-that all null hypotheses are true simultaneously-which is rarely of interest or use to researchers. Moreover, we are confident that the adjusted level does not alter the principal conclusions of the study.

Despite these recognised limitations, the study provides useful insights into the potential value of an LTNC register and its associated tools as a means to monitor needs, inputs and outcomes for patients with LTNC. It identifies significant gaps in service provision of both health and social services support in comparison with individual needs.

The study demonstrates that a registry would be feasible and acceptable to most patients. We suggest that face-to-face interviews conducted as a part of integrated care planning are likely to offer a better opportunity for both information gathering and reassessment of needs against which the adequacy of services delivered may be evaluated. The inverse therapy effect is an important but little recognised phenomenon, reflecting the fact that those patients who remain dependent continue to require and consume the bulk of available resources. This is always likely to be a confounder to be taken account of in longitudinal observational studies that seek to establish a relationship between more intensive rehabilitation and better outcomes.

Author affiliations

${ }^{1}$ School of Public Health and Psychosocial Studies and School of Rehabilitation and Occupational Studies, AUT University, Auckland, New Zealand 
${ }^{2}$ Department of Palliative Care, Policy and Rehabilitation, School of Medicine, King's College London, London, UK

${ }^{3}$ Institute of Neurology, University College London, London, UK

${ }^{4}$ South London and Maudsley NHS Foundation Trust, London, UK

${ }^{5}$ Regional Rehabilitation Unit, Northwick Park Hospital, London, UK

Acknowledgements The authors gratefully acknowledge the hard work of the clinical teams in the nine centres, and of the patients and their families who participated in the follow-up survey. Special thanks to Helena Morris, Sasha Wade, Bernadette Khoshaba, Christine O'Connell, Amanda Fahy, Ralph Crook and Ali Price for their roles in data collection and administrative support for the project. Statistical advice was provided by Paul Bassett, Statsconsultancy Ltd.

Contributors RJS was the principal investigator for the larger study of which this formed a part. He took the lead role in execution and governance of the study and had overall responsibility for study reporting. LT-S was the lead clinician, led the design of the study, and the development of the long-term neurological conditions register and dataset. LT-S and RJS wrote the first draft of the article together. DMJ was responsible for data-checking and quality and also contributed to writing the article. EDP and SF were coapplicants on the study and members of the project steering group, contributing to direction and decision-making as the study progressed. All coauthors reviewed and commented on the manuscript.

Funding This article presents independent research commissioned by the National Institute for Health Research Health Services and Delivery Research (NIHR HS\&DR) programme (project number 08/1809/235). Please visit the HS\&DR website for more information. Financial support for this article was also provided by the Dunhill Medical Trust and the Luff Foundation.

Competing interests LT-S, DMJ and RJS have received financial support from the NIHR to attend conferences to disseminate the submitted work. LT-S was the lead developer of the Northwick Park Dependency Scale (NPDS), Neurological Impairment Scale (NIS) and Needs and Provision Complexity Scale (NPCS).

Patient consent Obtained.

Ethics approval Approval for the study was granted by Bromley Research Ethics Committee (Ref no: 09/H0805/25) and subsequently the R\&D centres of the seven participating National Health Service (NHS) trusts. The remaining two recruiting centres were in the independent sector-approval for recruitment was obtained through their internal clinical and research governance processes.

Provenance and peer review Not commissioned; externally peer reviewed.

Data sharing statement The results presented in this article represent the first publication of findings from the larger study, for which the complete and final report is available from http://www.nets.nihr.ac.uk/projects/hsdr/ 081809235 (accessed 9 January 2014). Not available at the current time as further articles are currently in development. Data sharing may be available in the future-please contact the corresponding author.

Disclaimer The views expressed in this article are those of the authors and not necessarily those of the NHS, the NIHR or the Department of Health.

Open Access This is an Open Access article distributed in accordance with the Creative Commons Attribution Non Commercial (CC BY-NC 3.0) license, which permits others to distribute, remix, adapt, build upon this work noncommercially, and license their derivative works on different terms, provided the original work is properly cited and the use is non-commercial. See: http:// creativecommons.org/licenses/by-nc/3.0/

\section{REFERENCES}

1. Barnes MP, Rademacher $\mathrm{H}$. Neurological rehabilitation in the community. J Rehabil Med 2001;33:244-8.

2. Altman IM, Swick S, Malec JF. Effectiveness of home- and community-based rehabilitation in a large cohort of patients disabled by cerebrovascular accident: evidence of a dose-response relationship. Arch Phys Med Rehabil 2013;94:1837-41.
3. Geurtsen GJ, van Heugten CM, Martina JD, et al. Comprehensive rehabilitation programmes in the chronic phase after severe brain injury: a systematic review. J Rehabil Med 2010;42:97-110.

4. Kendall $\mathrm{E}$, Muenchberger $\mathrm{H}$, Catalano $\mathrm{T}$. The move towards community-based rehabilitation in industrialised countries: are we equipped for the challenge? Disabil Rehabil 2009;31:2164-73.

5. Jianjun $\mathrm{Y}$, Yongshan $\mathrm{H}, \mathrm{Wu} \mathrm{Y}$, et al. The effects of community-based rehabilitation on stroke patients in China: a single-blind, randomized controlled multicentre trial. Clin Rehabil 2009;23:408-17.

6. Bartolo M, De Luca D, Serrao M, et al. Caregivers burden and needs in community neurorehabilitation. J Rehabil Med 2010;42:818-22.

7. Jackson D, Turner-Stokes L, Murray J, et al. Acquired brain injury and dementia: a comparison of carer experiences. Brain Inj 2009;23:433-44.

8. Harding KE, Taylor NF, Leggat SG, et al. Prioritizing patients for community rehabilitation services: do clinicians agree on triage decisions? Clin Rehabil 2010;24:928-34.

9. Kendall E, Buys N, Larner J. Community-based service delivery in rehabilitation: the promise and the paradox. Disabil Rehabil 2000;22:435-45.

10. Kendall E, Muenchberger $\mathrm{H}$, Catalano $\mathrm{T}$, et al. Developing core interprofessional competencies for community rehabilitation practitioners: findings from an Australian study. $J$ Interprof Care 2011;25:145-51.

11. Nancarrow S, Moran A, Freeman J, et al. Looking inside the black box of community rehabilitation and intermediate care teams in the United Kingdom: an audit of service and staffing. Qual Prim Care 2009;17:323-33.

12. Department of Health. Saving lives: our healthier nation. London, England: Department of Health, 1999.

13. Department of Health. The national service framework for long-term conditions. London: Department of Health, 2005.

14. Turner-Stokes L, Whitworth $D$. National service framework for long-term conditions: the challenges ahead. Clin Med 2005;5:203-6.

15. Williams R, Wright J. Epidemiological issues in health needs assessment. BMJ 1998;7141:1379-82.

16. Barnes MP, Radermacher $\mathrm{H}$. Community rehabilitation in neurology. Cambridge University Press, 2003.

17. Gladman J, Radford KA, Edmans JA, et al. Specialist rehabilitation for neurological conditions: literature review and mapping study. The University of Nottingham, 2007

18. Newton J, Garner S. Disease registers in England. Oxford: Institute of Health Sciences, 2002.

19. Turner-Stokes L, Thu A, Williams $\mathrm{H}$, et al. The Neurological Impairment Scale: factor structure, reliability and utility as a predictor of functional outcome in neurorehabilitation. Disabil Rehabil 2014;36:23-31.

20. Turner-Stokes L, McCrone P, Jackson DM, et al. The Needs and Provision Complexity Scale: a multicentre prospective cohort analysis of met and unmet needs and their cost implications for patients with complex neurological disability. BMJ Open 2013;3:pii: e002353.

21. Turner-Stokes L, Tonge $P$, Hunter $M$, et al. The Northwick Park Dependency Score-a measure of nursing dependency in rehabilitation. Clin Rehabil 1998;12:304-16.

22. Jackson D, Turner-Stokes L, McPherson KM, et al. Acquired brain injury: impact on carers. Department of Health, 2011.

23. Jackson D, Williams D, Turner-Stokes L, et al. How do carers of people with long term neurological conditions experience the provision of replacement care? London: Final report to the Department of Health, 2011.

24. Siegert RJ, Jackson DM, Tennant A, et al. Factor analysis and Rasch analysis of the Zarit burden interview for acquired brain injury carer research. J Rehabil Med 2010;42:302-9.

25. Jackson D, Turner-Stokes L, Harris J, et al. Support for LTNC carers, particularly those with multiple caring roles: an investigation of support needs and the cost of provision. London: Final report to the Department of Health, 2011.

26. Turner-Stokes L, Nyein K, Turner-Stokes T, et al. The UK FIM+FAM development and evaluation. Clin Rehabil 1999;13:277-87.

27. Siegert RJ, Turner-Stokes L. The Needs and Provision Complexity Scale: a first psychometric analysis using multicentre data. Clin Rehabil 2014. [Epub ahead of print 22 Jan 2014].

28. Siegert RJ, Turner-Stokes L. A psychometric evaluation of the Northwick Park Dependency Scale (NPDS). J Rehabil Med 2010;42:936-43.

29. Turner-Stokes L, Williams H, Howley D, et al. Can the Northwick Park Dependency Scale be translated to a Barthel Index? Clin Rehabil 2010;24:1112-20.

30. Turner-Stokes L, Nyein K, Halliwell D. Care needs assessmentdirectly costable outcome measure for rehabilitation. Clin Rehabil 1999;13:253-68. 
31. Sander A, Seel R, Kreutzer J, et al. Agreement between persons with traumatic brain injury and their relatives regarding psychosocial outcome using the Community Integration Questionnaire. Arch Phys Med Rehabil 1997;78:353-7.

32. Sander A, Fuchs K, High W Jr, et al. The Community Integration Questionnaire revisited: an assessment of factor structure and validity. Arch Phys Med Rehabil 1999;80:1303-8.

33. Zarit SH, Zarit JM. The Burden Interview: gerontology centre. Pennsylvania State University, 1990.

34. Visser-Meily JMA, Post MWM, Riphagen I, et al. Measures used to assess burden among caregivers of stroke patients: a review. Clin Rehabil 2004;18:601-23.

35. Higginson IJ, Gao W, Jackson D, et al. Short-form Zarit Caregiver Burden Interviews were valid in advanced conditions. J Clin Epidemiol 2010;63:535-42.

36. British Society of Rehabilitation Medicine. Specialist neurorehabilitation services: providing for patients with complex rehabilitation needs. London, 2010. http://www.bsrm.co.uk/ClinicalGuidance/ Levels_of_specialisation_in_rehabilitation_services5.pdf (accessed 17 Feb 2014).
37. Siegert RJ, McCrone P, Jackson D, et al. Evaluation of community rehabilitation service delivery in long-term neurological conditions. Final Report. NIHR Service Delivery and Organisation Programme, 2013.

38. Corrigan JD, Harrison-Felix C, Bogner J, et al. Systematic bias in traumatic brain injury outcome studies because of loss to follow-up. Arch Phys Med Rehabil 2003;84:153-60.

39. Wade DT, Crawford S, Wenden FJ, et al. Does routine follow-up after head injury help? A randomised controlled trial. $J$ Neurol Neurosurg Psychiatry 1997:62:478-84.

40. Koffman J, Gao W, Goddard C, et al. Progression, symptoms and psychosocial concerns among those severely affected by multiple sclerosis: a mixed-methods cross-sectional study of black Caribbean and white British people. PLOS ONE 2013;8:e75431.

41. Switzer G, Bruce J, Myaskovsky L, et al. Race and ethnicity in decisions about unrelated hematopoietic stemcell donation. Blood 2013;121:1469-76

42. Young $\mathrm{J}$. Is stroke better managed in the community. BMJ 1994;309:1356-8.

43. Perneger T. What's wrong with Bonferroni adjustments. BMJ 1998;316:1236-8. 